\title{
Aplicação de técnicas de geoprocessamento na seleção de áreas aptas à implantação de aterro sanitário no Portal do Pantanal
}

\author{
Application of geoprocessing techniques in the selection of suitable areas for landfill implantation \\ in the Portal do Pantanal
}

Aplicación de técnicas de geoprocesamiento en la selección de áreas adecuadas para la

implementación de un relleno sanitario en el Portal do Pantanal

Recebido: 23/09/2021 | Revisado: 30/09/2021 | Aceito: 05/10/2021 | Publicado: 09/10/2021

\author{
Rodrigo Martins Moreira \\ ORCID: https://orcid.org/0000-0001-6794-6026 \\ Universidade Federal de Rondônia, Brasil \\ E-mail: rodrigo.moreira@unir.br \\ Fabrício Bau Dalmas \\ ORCID: https://orcid.org/0000-0001-7547-6642 \\ Universidade Guarulhos, Brasil \\ E-mail: fbdalmas@gmail.com \\ Antonio Conceição Paranhos Filho \\ ORCID: https://orcid.org/0000-0002-9838-5337 \\ Universidade Federal de Mato Grosso do Sul, Brasil \\ E-mail: antonio.paranhos@pq.cnpq.br
}

\begin{abstract}
Resumo
A gestão e a disposição inadequada dos resíduos sólidos podem causar impactos socioambientais, tais como degradação do solo e comprometimento dos corpos hídricos. O objetivo desta pesquisa foi elaborar um mapa de aptidão para implantação de aterro sanitário no Município de Coxim, localizado no Estado de Mato Grosso do Sul, que tem posição estratégica para conversação dos recursos naturais do Cerrado e do Pantanal. Como metodologia foi aplicada a Análise Hierárquica, considerando os seguintes fatores: declividade; hidrografia; uso e ocupação do solo; vegetação; e malha viária. Utilizou-se a plataforma de Sistema de Informações Geográficas ArcGis para elaboração dos mapas e para a Análise Multicritério, que envolveu os fatores supracitados, da qual resultou o mapa de aptidão para instalação de aterros sanitários no município. Concluiu-se que $45 \%$ da área do município é apta a receber um aterro sanitário. Estes resultados, se aplicados no gerenciamento urbano e ambiental do município, poderão reduzir os custos com logística final dos resíduos sólidos urbanos e, assim, diminuir a pegada ecológica dos processos de gerenciamento.
\end{abstract}

Palavras-chave: Bioma cerrado; Gerenciamento de resíduos sólidos urbanos; Planejamento urbano.

\begin{abstract}
The management and improper disposal of solid waste can cause social and environmental impacts, such as soil degradation and water bodies compromise. The objective of this research was to elaborate an aptitude map for landfill implantation in Coxim Municipality, located in Mato Grosso do Sul State, which has a strategic position for conversation of Cerrado and Pantanal natural resources. As methodology was applied the Hierarchical Analysis, considering the following factors: slope; hydrography; land use and occupation; vegetation; and road network. The ArcGis Geographic Information System platform was used for the elaboration of the maps and for the Multicriteria Analysis, which involved the aforementioned factors, which resulted in the suitability map for the installation of landfills in the municipality. It was concluded that $45 \%$ of the area of the municipality is able to receive a landfill. These results, if applied to the urban and environmental management of the municipality, may reduce the costs with final logistics of urban solid waste and thus reduce the ecological footprint of management processes.

Keywords: Cerrado biome; Urban solid waste management; Urban planning.
\end{abstract}

\section{Resumen}

El manejo y disposición inadecuados de los desechos sólidos puede generar impactos sociales y ambientales, como la degradación del suelo y daños a los cuerpos de agua. El objetivo de esta investigación fue elaborar un mapa de idoneidad para la implantación de un relleno sanitario en el Municipio de Coxim, ubicado en el Estado de Mato Grosso do Sul, que tiene una posición estratégica para la conversación de los recursos naturales del Cerrado y el Pantanal. Como metodología se aplicó el Análisis Jerárquico, considerando los siguientes factores: pendiente; hidrografía; uso y ocupación de la tierra; vegetación; y red de carreteras. Para la elaboración de los mapas y para el 
Análisis Multicriterio se utilizó la plataforma del Sistema de Información Geográfica ArcGis, que involucró los factores antes mencionados, lo que resultó en el mapa de idoneidad para la instalación de rellenos sanitarios en la ciudad. Se concluyó que el $45 \%$ del área del municipio es apta para recibir un relleno sanitario. Estos resultados, si se aplican en la gestión urbana y ambiental del municipio, pueden reducir los costos con la logística final de los residuos sólidos urbanos y, así, reducir la huella ecológica de los procesos de gestión.

Palabras clave: Bioma cerrado; Gestión de residuos sólidos urbanos; Urbanismo.

\section{Introdução}

Um dos maiores desafios com que se defronta a sociedade moderna é o equacionamento da geração excessiva e da disposição final ambientalmente segura dos resíduos sólidos (Deus; Battistelle, 2015). O gerenciamento de resíduos sólidos é um dos principais temas na agenda de países em todo o mundo. A geração de resíduos no Brasil é de 214.868 toneladas por dia, sendo 1,035 kg.hab-1.dia-1. Ainda, 40,9\% dos resíduos coletados foram dispostos de maneira inadequada por 3.352 municípios, são 29 milhões de toneladas enviados à lixões. A região Centro-Oeste produziu em 2017 um total de resíduos de 0,978 kg.hab-1.dia-1, onde 3,6 toneladas são enviadas diariamente para lixões (Abrelpe, 2021).

A gestão e a disposição inadequada dos resíduos sólidos causam impactos socioambientais, tais como degradação do solo, comprometimento dos corpos d'água e mananciais, intensificação de enchentes, contribuição para a poluição do ar e proliferação de vetores de importância sanitária nos centros urbanos e catação em condições insalubres nas ruas e nas áreas de disposição final (Dalmas et al., 2011). Além do expressivo aumento da geração desses resíduos, observam-se, ainda, ao longo dos últimos anos, mudanças significativas em sua composição e características e o aumento de sua periculosidade (DE Franceschi, 2017).

Em relação à responsabilidade pela gestão dos resíduos sólidos urbanos, o Artigo 10 da Política Nacional dos Resíduos Sólidos (Lei Federal 12.305/2010) traz em seu texto que a responsabilidade sobre a gestão integrada dos resíduos sólidos gerados em determinado território cabe ao Distrito Federal, municípios e ao próprio gerador. Há então, responsabilidade dos municípios (Colman et al., 2016).

Os métodos de gestão dos resíduos sólidos domiciliares envolvem a sua redução (reutilização, reciclagem, compostagem e incineração) e correta disposição final, em aterros sanitários. Os lixões, maneira inadequada para disposição final, podem desencadear expressivos impactos ambientais, decorrentes da produção de chorume ou percolado, substância orgânica produzida por microorganismos, através da decomposição da matéria orgânica presente nos resíduos sólidos. Entre os impactos pode-se citar a poluição de águas subterrâneas e de superfície, além do solo e ar (IPT, 2000).

Outro grande impacto que pode ser ocasionado pela presença de lixões é o social, relacionado à população vizinha à área, que fica vulnerável a moléstias, infestação de insetos e roedores. Ainda há a problemática dos catadores de recicláveis que atuam, muitas vezes, no lixão, podendo haver também o trabalho infantil, onde crianças são expostas a acidentes e contaminações (Dalmas et al., 2011).

O processo de coleta seletiva dos resíduos sólidos urbanos pode resultar na mistura de materiais que, em algumas situações, dificilmente são separados pelos processos de triagem. Assim, como consequência, tanto as usinas de compostagem quanto as técnicas de coleta seletiva geram rejeitos que obrigatoriamente devem ser descartados. Processo semelhante ocorre com os incineradores, que podem reduzir o volume do resíduo a uma proporção de 5 a $15 \%$ do volume original, gerando escórias e cinzas que precisam ser descartadas corretamente (CETESB, 1997). A implantação de aterros sanitários não tem como objetivo o tratamento ou a reciclagem dos materiais presentes no lixo urbano, mas o armazenamento de resíduo final no solo, o que requer estudo para seleção de áreas, uma vez que os espaços úteis a essa técnica tornam-se cada vez mais escassos (Lima, 1995).

As várias técnicas de seleção de áreas adequadas para a instalação de aterros sanitários, via de regra, se valem das geotecnologias, por meio da utilização de produtos de sensoriamento remoto e de Sistema de Informações Geográficas (SIG) 
nas diversas etapas de gestão (Colman et al., 2016).

Os Sistemas de Informações Geográficas são ferramentas chave para a gestão ambiental, em específico para a gestão de resíduos sólidos. O uso de SIG traduz-se em um conjunto de técnicas de coleta, armazenamento, consulta, processamento e apresentação de informações geográficas. É uma ferramenta de apoio à tomada de decisão que apresenta baixo custo, e a possibilidade de estudo de áreas extensas (Dalmas et al., 2011; de Franceschi et al., 2017; Poague, 2018).

A presente pesquisa teve o objetivo de elaborar o mapa de aptidão para implantação de aterro sanitário no município de Coxim, localizado no Estado de Mato Grosso do Sul. Mapas temáticos foram considerados como critérios estratégicos e sobrepostos em uma plataforma de SIG. O método AHP foi empregado para a hierarquização dos critérios de entrada. O produto final é um mapa classificando áreas de acordo com sua aptidão para implantação de aterro sanitário no Município de Coxim, MS. Essa ferramenta é fundamental para o plano diretor e zoneamento ambiental do município.

\section{Metodologia}

Devido ao fato de ser uma pesquisa envolvendo um Sistema de Informações Geográficas, onde foram aplicadas técnicas de Sensoriamento Remoto, esta pesquisa é classificada como de natureza qualitativa (Ludke e Andre, 2013 apud Pereira, 2018). Neste tipo de metodologia o pesquisador coloca em prática os métodos, focados no seus objetivos, sem ter previsão de como poderá ser a conclusão. Esta pesquisa qualitativa envolveu dados secundários como imagens de satélite e base de dados de fontes confiáveis, como do Instituto Brasileiro de Geografia e Estatística (IBGE) e Instituto de Pesquisas Espaciais (INPE).

\section{1 Área de estudo}

O Município de Coxim-MS está situado no sul da região Centro-Oeste do Brasil, no norte de Mato Grosso do Sul (Figura 1). Localiza-se na latitude de $18^{\circ} 30^{\prime} 25^{\prime \prime}$ sul e longitude de 5445’36” oeste. Possuía em 2019 uma população estimada em 33.543 habitantes; e possui um dos maiores rebanhos de bovinos de Mato Grosso do Sul (IBGE, 2021). O clima é tropical, de acordo com a Köppen e Geiger onde o clima é classificado como Aw, por apresentar inverno seco, verão chuvoso, e pode perceber nitidamente a estação seca no inverno. A temperatura média do mês mais frio é superior a $18^{\circ} \mathrm{c}$, e as precipitações são acima de $750 \mathrm{~mm}$ anuais, $25.5^{\circ} \mathrm{C}$ é a temperatura média em Coxim.

Figura 1. Mapa com a localização do Município de Coxim (MS).

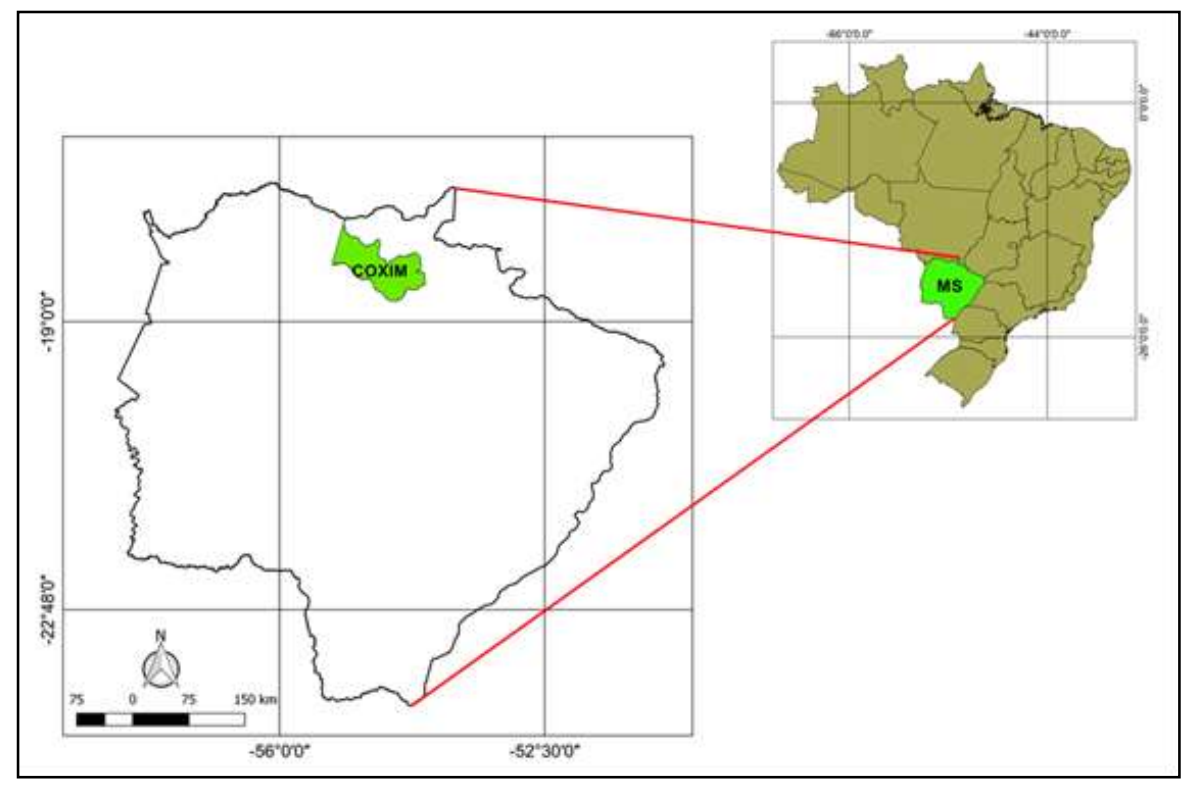

Fonte: Autores. 


\subsection{Aquisição das imagens}

As imagens usadas para mostrar a evolução da ocupação do lixão do Município de Coxim, MS, foram adquiridas a partir do software Google Earth (GOOGLE, 2021), com datas referentes aos dias 17 de junho de 2003 e 01 de agosto de 2018. As imagens foram exportadas com a extensão JPEG e abertas no software ArcGis versão 10.2 para registro. O registro de imagens de satélite baseia-se no princípio de inserir um sistema de referência de coordenadas geográficas. O sistema inserido foi o datum WGS84. As imagens foram registradas utilizando a ferramenta georeferencing. Pontos de controle foram selecionados utilizando o software Google Earth, então, foram encontrados nas imagens exportadas no software ArcGis v10.2 e corrigidas as coordenadas. O método de correção geométrica utilizado foi o polinomial de primeira ordem.

\subsection{Seleção dos critérios}

Os critérios utilizados foram selecionados de acordo com a publicação do Sistema Nacional de Saneamento Ambiental (NURENE, 2008) sobre Resíduos sólidos: projeto, operação e monitoramento de aterros sanitários: guia do profissional em treinamento. Os critérios utilizados são apresentados na Tabela 1.

Tabela 1. Critérios, grau de aptidão e valores restritivos para elaboração dos mapas e análise multicritério.

\begin{tabular}{|c|c|c|}
\hline CRITÉRIOS & APTIDÃO & VALORES RESTRITIVOS \\
\hline \multirow[t]{4}{*}{ Distância de corpos hídricos } & Não apto & $<200$ metros \\
\hline & Moderadamente apto & $200-499$ metros \\
\hline & Apto & $500-1000$ metros \\
\hline & Muito apto & $>1000$ metros \\
\hline \multirow[t]{3}{*}{ Uso e ocupação do solo } & Não apto & Vegetação nativa \\
\hline & Apto & Agricultura \\
\hline & Muito apto & Solo exposto \\
\hline \multirow[t]{5}{*}{ Distância de Área urbana } & Não apto & $100-250$ metros \\
\hline & Pouco apto & $250-500$ metros \\
\hline & Moderadamente apto & $500-1000$ metros \\
\hline & Apto & 1000 - 2000 metros \\
\hline & Muito apto & $>2000$ \\
\hline \multirow[t]{4}{*}{ Distância de Malha rodoviária } & Não apto & $<100$ metros \\
\hline & Moderadamente apto & $100-499$ metros \\
\hline & Apto & $500-1000$ metros \\
\hline & Muito apto & 1000 metros \\
\hline \multirow[t]{5}{*}{ Declividade } & Não apto & $>30$ \\
\hline & Pouco apto & $20-30$ \\
\hline & Moderadamente apto & $10-19,9$ \\
\hline & Apto & $3-9,9$ \\
\hline & Muito apto & $<3$ \\
\hline \multirow[t]{4}{*}{ NDVI } & Não apto & Vegetação densa \\
\hline & Pouco apto & Vegetação rasteira \\
\hline & Apto & Gramínea \\
\hline & Muito apto & Solo exposto \\
\hline
\end{tabular}

Fonte: Autores. 


\subsubsection{Distância de corpos hídricos}

Corpos hídricos são abundantes na região de estudo. Sua importância respalda-se no fato de a área possuir interesse estratégico por ser o Portal do Pantanal. Os rios Jaru e Coxim são os principais formadores do Rio Taquari. Esse último é responsável pelo megaleque aluvial do Taquari no Pantanal. Logo, os aterros devem ser estrategicamente alocados a distâncias mínimas seguras para garantia da não contaminação de corpos hídricos. Na Tabela 2 constam os valores mapeados.

Tabela 2. Valores referentes à aptidão para instalação de aterro sanitário de acordo com os critérios de distância da Hidrografia.

\begin{tabular}{cc}
\hline CLASSE & ÁREA $(\%)$ \\
\hline Muito baixa aptidão & 5 \\
Moderada aptidão & 6,73 \\
Alta aptidão & 10,27 \\
Muito alta aptidão & 78 \\
\hline
\end{tabular}

Fonte: Autores.

Os dados quanto à distribuição dos corpos hídricos foram obtidos a partir do sistema Hidroweb v2.0.0.4 (ANA, 2019), apresentados na Figura 2. Os dados são provenientes da Base Hidrográfica Ottocodificada Multiescalas (ANA, 2017).

Figura 2. Mapa indicando as áreas aptas para implantação de aterro sanitário no Município de Coxim com critérios restritivos a distância de Hidrografia.

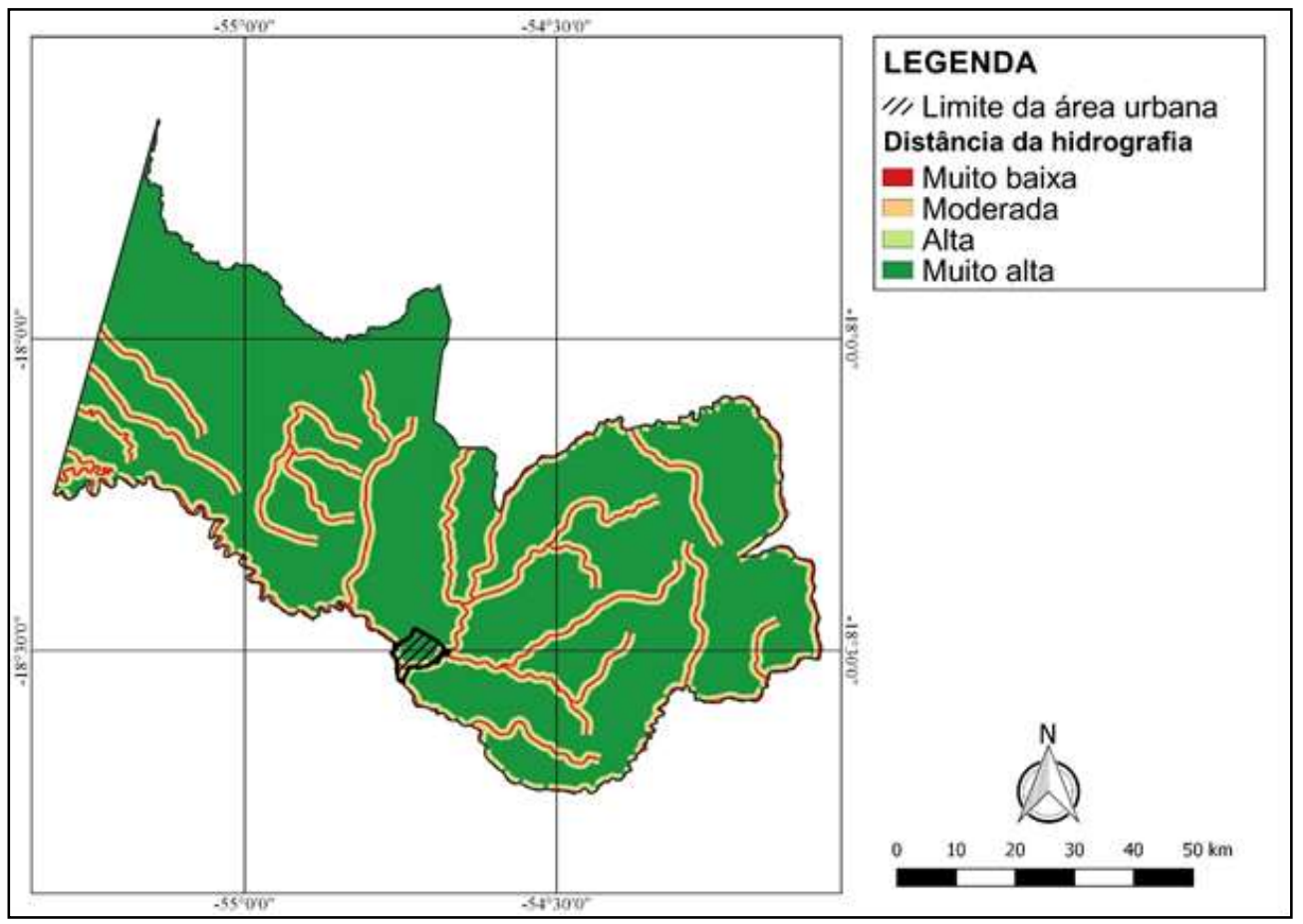

Fonte: Autores.

\subsubsection{Uso e ocupação do solo}

A imagem para a classificação do uso e ocupação do solo foi obtida a partir da plataforma USGS. A cena utilizada foi a LC82250732018252LGN00, com identificação do produto LC08_L1TP_225073_20180909_20180912_01_T1. A data e horário de coleta da imagem pelo satélite é 2018-09-12, 23:59:58, respectivamente. O sensor utilizado foi o Operational Land 
Imager (OLI), com 30 metros de resolução espacial. Na Tabela 3 apresenta-se os valores mapeados; e a Figura 3 apresenta as classes de Uso e Ocupação do Solo do Município de Coxim.

Tabela 3. Valores referentes à aptidão para instalação de aterro sanitário de acordo com os critérios de Uso e Ocupação do Solo.

\begin{tabular}{llc}
\hline & CRITÉRIO & ÁREA (\%) \\
\hline \multirow{3}{*}{ Uso e ocupação do solo } & Muito baixa aptidão (vegetação nativa) & 3 \\
& Alta aptidão (agricultura) & 55 \\
& Muito alta aptidão (solo exposto) & 42 \\
\hline
\end{tabular}

Fonte: Autores.

Figura 3. Mapa indicando as áreas aptas para implantação de aterro sanitário no Município de Coxim com critérios restritivos ao Uso e Ocupação do Solo.

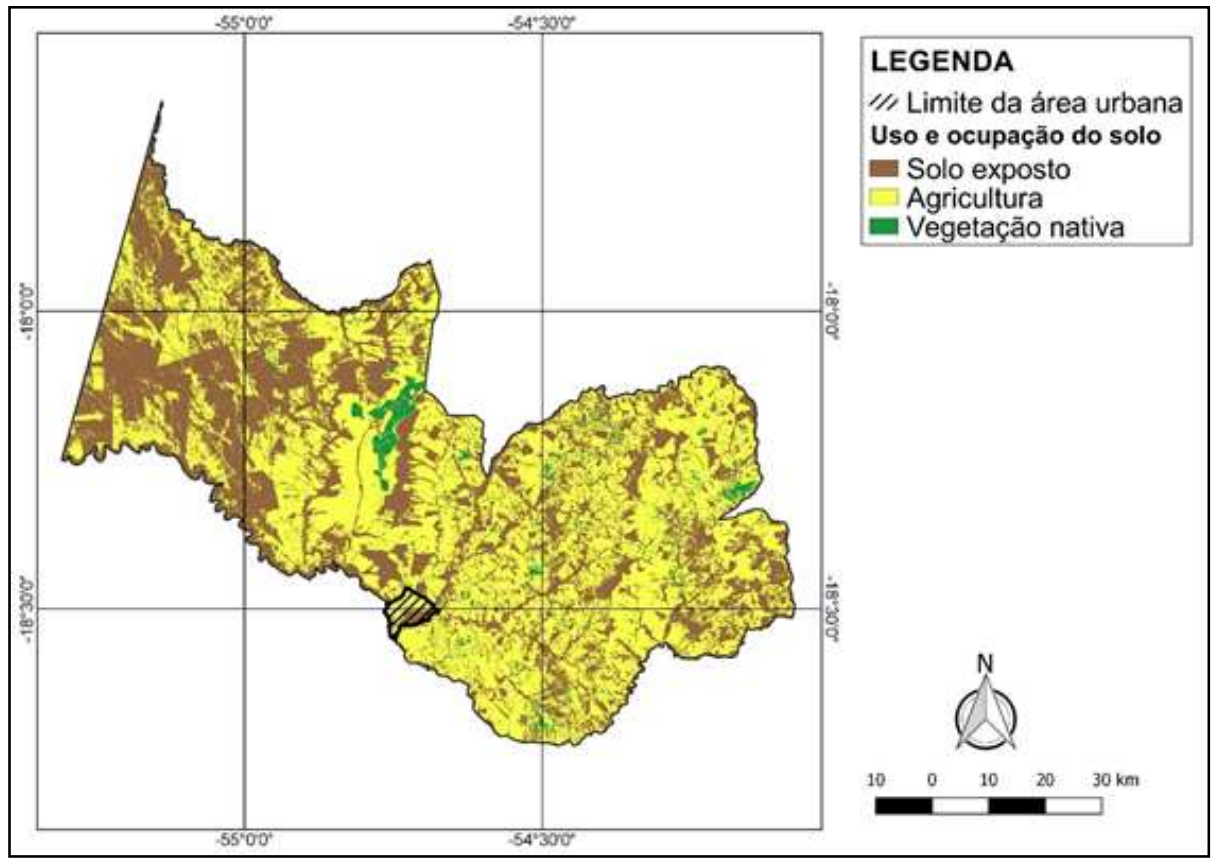

Fonte: Autores.

\subsubsection{Distância de Área Urbana}

A disposição final não adequada de resíduos sólidos a céu aberto traz sérios complicações à saúde pública, onde vetores de doenças podem causar sérios danos à comunidade próxima. Assim, assumiu-se uma distância mínima de 250 metros da área urbana para implantação do aterro sanitário, como mostrado na Figura 4. A distância do núcleo urbano é essencial quanto a custos de logística para envio dos resíduos. A Tabela 4 apresenta os valores relacionados à distância da zona urbana usados no cálculo da aptidão final. 
Figura 4. Mapa indicando as áreas aptas para implantação de aterro sanitário no Município de Coxim, com critérios restritivos a distância da Área Urbana.

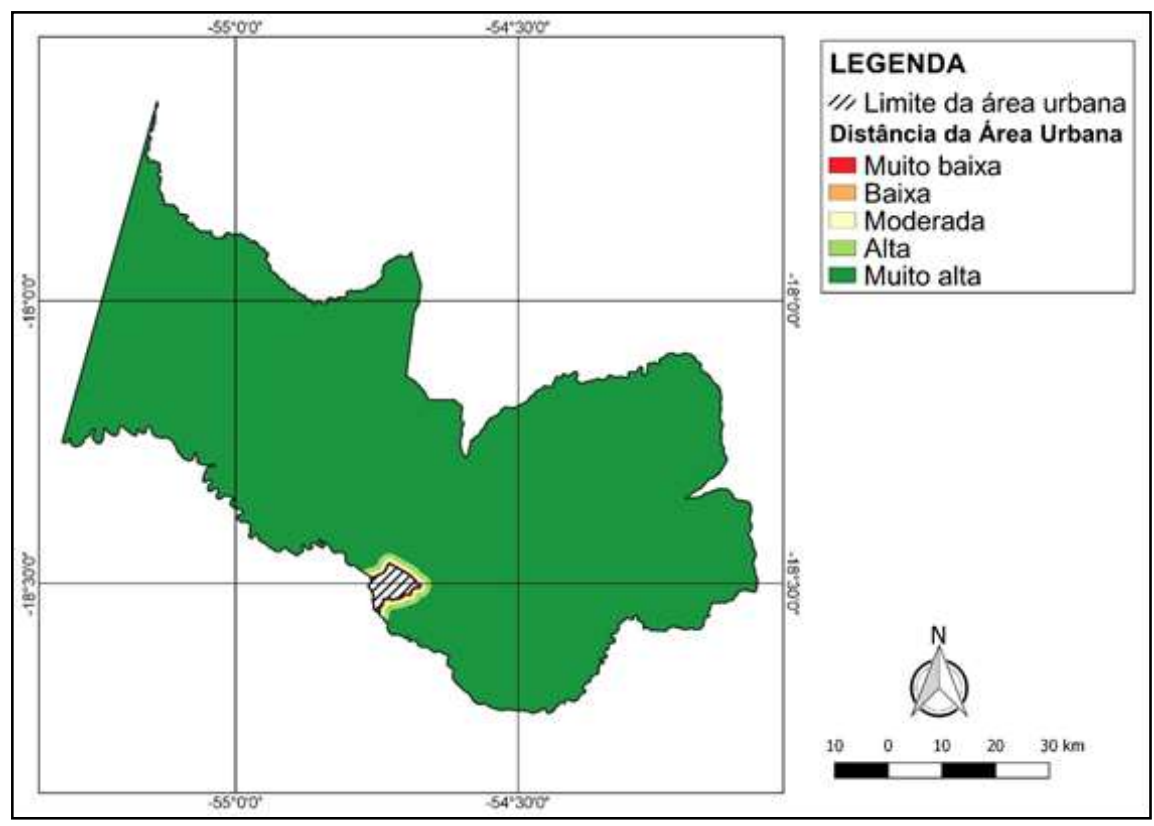

Fonte: Autores.

Tabela 4. Valores referentes à aptidão para instalação de aterro sanitário de acordo com os critérios de distância da Área Urbana do Município de Coxim, MS.

\begin{tabular}{clc}
\hline & CRITÉRIO & $\begin{array}{c}\text { ÁREA } \\
(\%)\end{array}$ \\
\hline \multirow{4}{*}{ Distância de Área urbana } & Muito baixa aptidão & 0,1 \\
& Baixa aptidão & 0,1 \\
& Moderada aptidão & 0,21 \\
& Alta aptidão & 0,44 \\
& Muito alta aptidão & 99,16 \\
\hline
\end{tabular}

Fonte: Autores.

\subsubsection{Distância de malha rodoviária}

Os dados para elaboração do mapa referente a malha rodoviária foram obtidos a partir da plataforma VGeo do Departamento Nacional de Infraestrutura de Transportes (DNIT, 20121). A distância do aterro sanitário a rodovias é essencial para efeito de custo com logística. Quanto mais distante, maior o custo. No entanto, é importante considerar os impactos que o lixão pode causar à comunidade que utiliza a malha rodoviária. Esse fator não foi considerado, visto que o objetivo da pesquisa é focado em impactos ambientais.

Utilizou-se uma distância mínima das rodovias de 100 metros. Essa distância é importante para evitar possíveis impactos ambientais, como odores, ruídos e alteração da dinâmica da paisagem. Assim, ao atribuir-se uma distância máxima também procura-se reduzir custos com logística. A Figura 5 apresenta o mapa com os valores restritivos à distância da malha rodoviária. A Tabela 5 mostra os valores utilizados para o mapeamento da aptidão. 
Figura 5. Mapa indicando a aptidão das áreas para implantação de aterro sanitário no município de Coxim, com critérios restritivos a distância da Malha Viária.

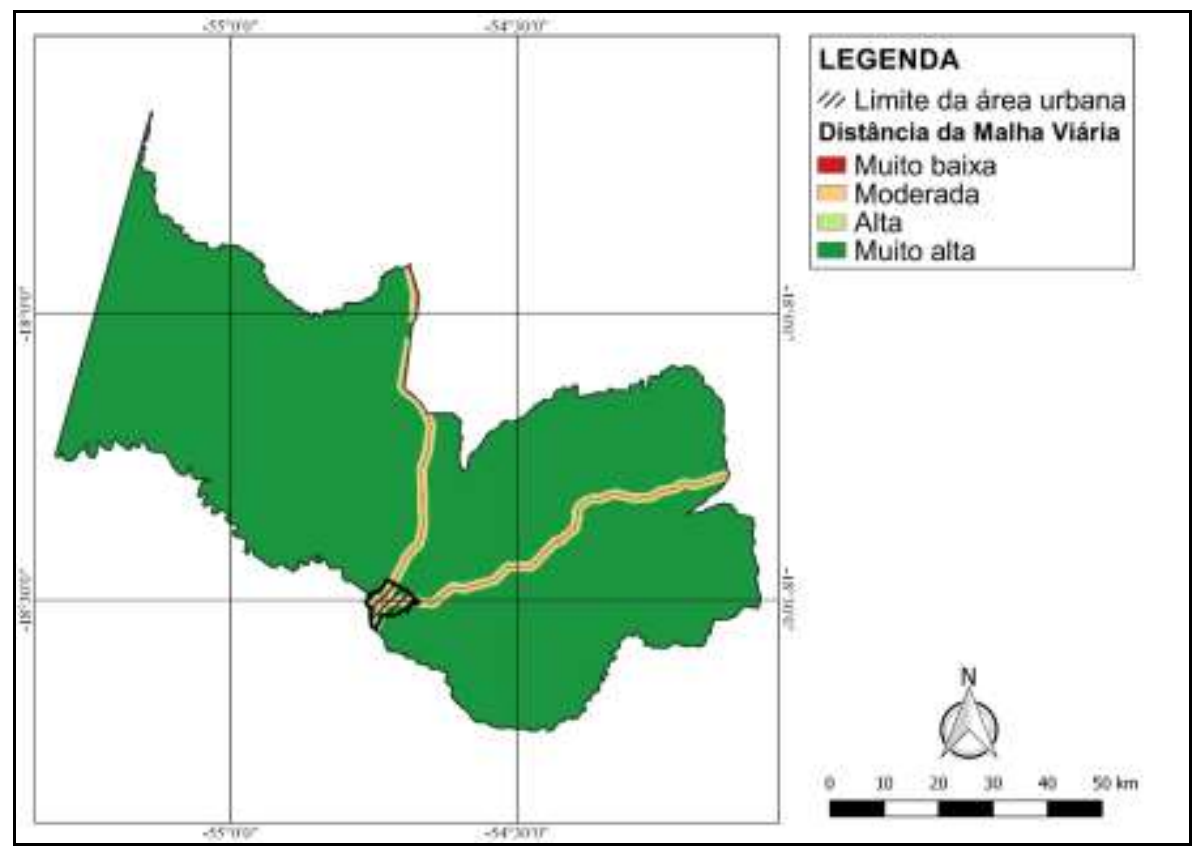

Fonte: Autores.

Tabela 5. Valores referentes à aptidão para instalação de aterro sanitário de acordo com os critérios de distância da Malha Viária.

\begin{tabular}{cc}
\hline CLASSE & ÁREA (\%) \\
\hline Muito baixa aptidão & 0,46 \\
Moderada aptidão & 1,74 \\
Alta aptidão & 2,06 \\
Muito alta aptidão & 95,74 \\
\hline
\end{tabular}

Fonte: Autores.

\subsubsection{Declividade}

Os dados para elaboração do modelo digital de elevação, e posterior classificação das declividades foram obtidos a partir da plataforma Topodata (INPE, 2011), com resolução espacial de 30 metros. Os dados Topodata são provenientes do programa Shutter Radar Topography Mission da agência United States of Geological Survey. A Tabela 6 apresenta os valores utilizados para o mapeamento final de aptidão. Na Figura 6 podem ser visualizadas as classes de declividade.

Tabela 6. Valores referentes à aptidão para instalação de aterro sanitário de acordo com os critérios de Declividade.

\begin{tabular}{|c|c|c|c|}
\hline \multicolumn{2}{|r|}{ CRITÉRIO } & DECLIVIDADE & ÁREA $(\%)$ \\
\hline \multirow{5}{*}{ Declividade } & Muito baixa aptidão & $>30 \%$ & 1 \\
\hline & Baixa aptidão & $20-30 \%$ & 1 \\
\hline & Moderada aptidão & $10-20 \%$ & 6 \\
\hline & Alta aptidão & $3-10 \%$ & 46 \\
\hline & Muito alta aptidão & $<3 \%$ & 46 \\
\hline
\end{tabular}

Fonte: Autores. 
Figura 6. Mapa indicando as áreas aptas para implantação de aterro sanitário no município de Coxim com critérios restritivos a declividade.

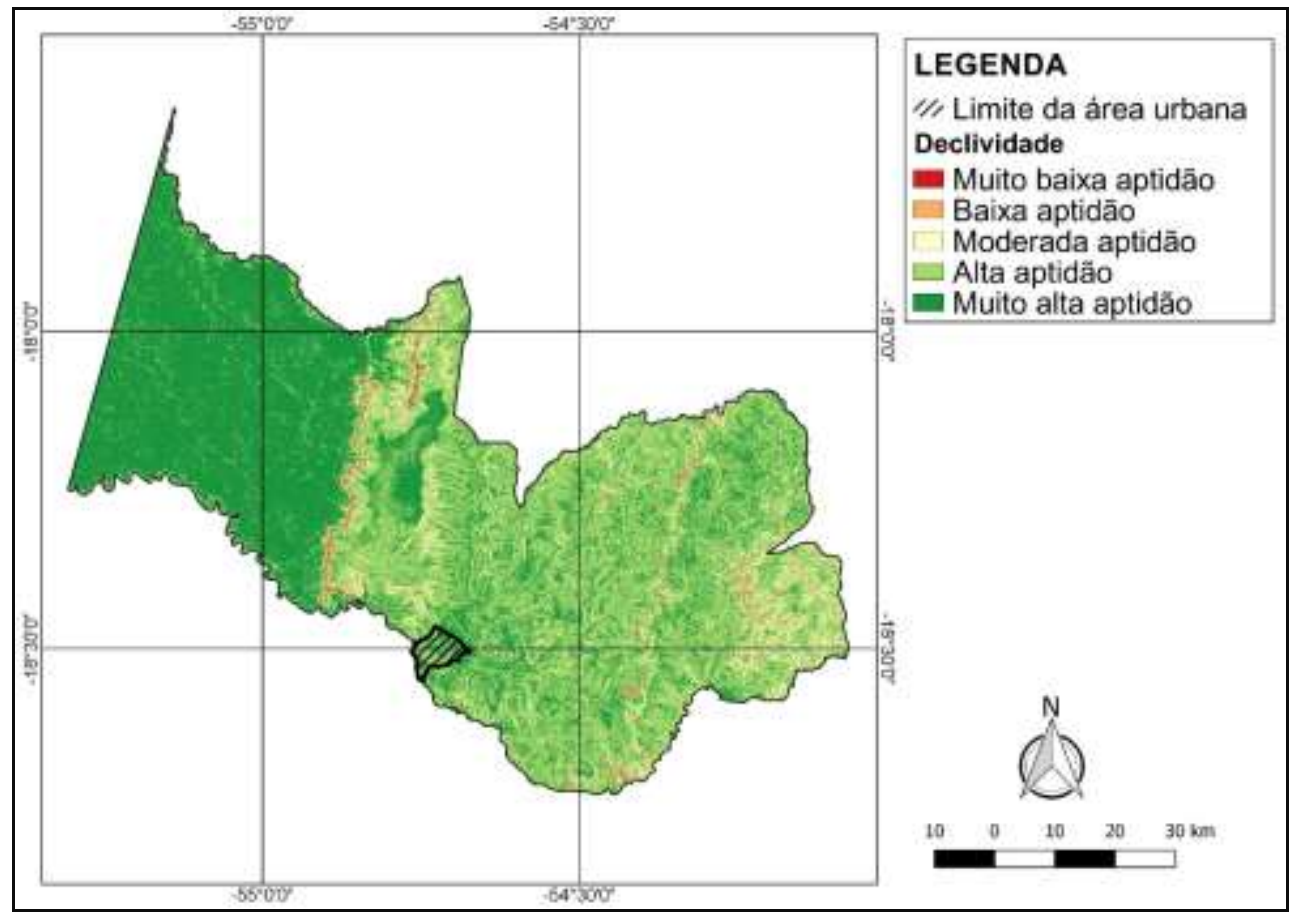

Fonte: Autores.

\subsection{6 Índice de Vegetação}

O Normalized Difference Vegetation Index (NDVI), em português Índice de Vegetação por Diferença Normalizada, foi elaborado por meio da metodologia proposta por Rouse et al. (1973). Usa-se as bandas do vermelho (RED) e infravermelho próximo (NIR), bandas 4 e 5 no do sensor OLI do satélite Landsat 8 (Equação 1).

$$
\text { Equação 1. } N D V I=\frac{(N I R-R E D)}{N I R+R E D}
$$

Os resultados da razão de bandas do NDVI mostram que valores próximos de 1 representam vegetação mais densa e saudável e valores próximos de -1 indicam, ausência de vegetação, solo exposto, áreas degradadas, corpos d’águas, áreas construídas, como apresentado na Figura 7. 
Figura 7. Mapa indicando as áreas aptas para implantação de aterro sanitário no município de Coxim com critérios restritivos o fitofisionomia da vegetação.

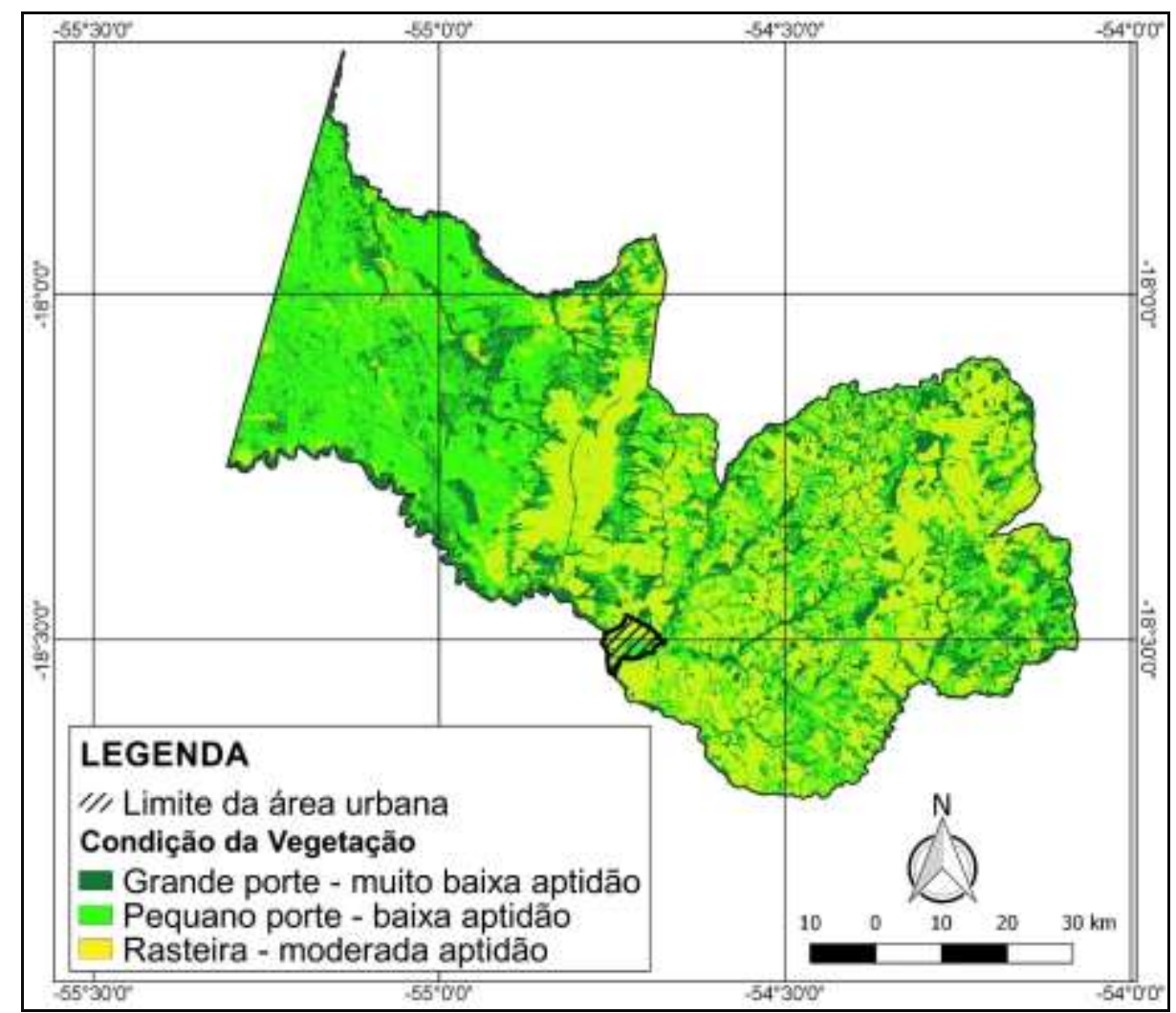

Fonte: Autores.

\subsubsection{Método da Análise Hierárquica}

Os valores restritivos almejam satisfazer objetivos específicos na tomada de decisão. Utilizou-se nessa pesquisa o processo de decisão de natureza multicritério, onde uma cadeia de restrições relacionada ao problema é considerada nos processos analíticos. Aplicou-se o método Analytic Hierarchy Process (AHP) por ser de fácil execução e possui uma ampla aplicabilidade na área ambiental. Ao aplicarem os critérios procuraram representar uma variação de aptidão, qualificando as áreas conforme o grau de adequação das características relevantes ao estudo. O método AHP (SAATY, 1990) transforma as comparações qualitativas em análises quantitativas, atribuindo grau de importância para diferentes critérios de maneira simultânea, permitindo uma tomada de decisão baseada em dados classificados de acordo com sua ordem de relevância.

O primeiro passo para a execução da AHP é o preenchimento da matriz de comparação “par-a-par” (Tabela 7). Essa etapa contou com a participação de quatro técnicos da Prefeitura de Coxim, MS. O Quadro 1 apresenta a escala de Saaty com os pesos e suas significâncias.

Tabela 7. Valores da escala de Saaty a distribuição dos pesos de julgamento para a tabela de comparação par-a-par.

\begin{tabular}{cc}
\hline GRAU DE IMPORTÂNCIA & DEFINIÇÃO \\
\hline 1 & Igual Importância entre os critérios \\
3 & Moderada Importância de critério in sobre jn \\
5 & Forte Importância de critério in sobre jn \\
7 & Importância Muito Forte de critério in sobre jn \\
9 & Importância Absoluta de critério in sobre jn \\
$2,4,6,8$ & Valores intermediários \\
\hline
\end{tabular}

Fonte: Autores. 
Research, Society and Development, v. 10, n. 13, e135101320992, 2021

(CC BY 4.0) | ISSN 2525-3409 | DOI: http://dx.doi.org/10.33448/rsd-v10i13.20992

Quadro 1. Pesos alocados para cada comparação par-a-par de critérios.

\begin{tabular}{|c|c|c|c|c|c|c|}
\hline & Declividade & $\begin{array}{c}\text { Uso e } \\
\text { ocupação }\end{array}$ & NDVI & Rodovias & Hidrografia & $\begin{array}{c}\text { Área } \\
\text { Urbana }\end{array}$ \\
\hline Declividade & 1 & 5 & 3 & 0.2 & 5 & 5 \\
\hline $\begin{array}{c}\text { Uso e } \\
\text { ocupação }\end{array}$ & 0.2 & 1 & 1 & 0.2 & 1 & 1 \\
\hline NDVI & 0.3 & 1 & 1 & 0.3 & 5 & 5 \\
\hline Rodovias & 5 & 5 & 3 & 1 & 9 & 7 \\
\hline Hidrografia & 0.2 & 1 & 0.2 & 0.1 & 1 & 1 \\
\hline Área Urbana & 0.2 & 1 & 0.2 & 0.1 & 1 & 1 \\
\hline
\end{tabular}

Fonte: Autores.

O terceiro passo é o cálculo do vetor de prioridade ou vetor de Eigen, que mostrará qual os pesos distribuídos entre os critérios. Os valores são obtidos a partir da Equação 2. Os resultados do vetor de Eigen são mostrados na Tabela 8 e Figura 8.

$$
\text { Equação 2. } \lambda \max =\frac{1}{n} \sum_{i=1}^{n} \frac{A w}{w i}
$$

Tabela 8. Grau de importância para cada critério de acordo com o Vetor de Eigen.

\begin{tabular}{ccc}
\hline CRITÉRIO & $\begin{array}{c}\text { VETOR DE } \\
\text { EIGEN }\end{array}$ & $\%$ \\
\hline Declividade & 0.24 & 23.94 \\
Uso e ocupação & 0.07 & 6.92 \\
NDVI & 0.15 & 14.72 \\
Rodovias & 0.45 & 44.97 \\
Hidrografia & 0.05 & 4.59 \\
Área Urbana & 0.05 & 4.86 \\
\hline
\end{tabular}

Fonte: Autores.

Figura 8. Grau de importância para cada critério de acordo com o Vetor de Eigen.

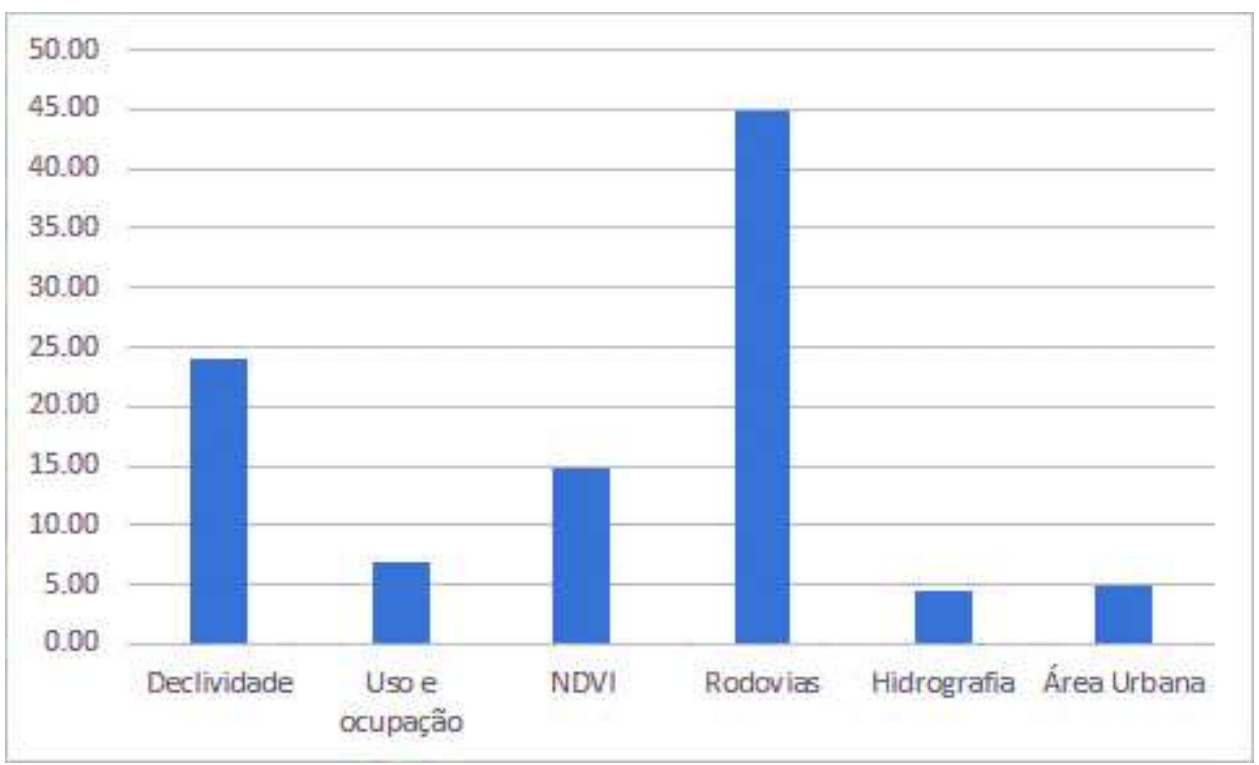

Fonte: Autores. 
Para a próxima etapa foi necessária a verificação da confiabilidade e consistência dos dados, analisando a aleatoriedade na atribuição dos pesos no preenchimento da matriz de comparação par-a-par. Para o cálculo do índice de consistência considerará o número principal do vetor de Eigen, $\lambda$ max e é obtido a partir da fórmula. Neste trabalho o valor encontrado para IC foi igual a 0,15. O Índice de Consistência é calculado pela Equação 3.

$$
\text { Equação 3. IC }=\frac{\lambda \max -n}{n-1}
$$

Então, foi calculada a Razão de Consistência (RC) que aferirá a aceitabilidade da aplicação do método. São tidos como aceitáveis valores abaixo de 0,10. Para isso utilizou-se a Equação 4. Neste trabalho o valor encontrado para RC foi de 0,1. O valor do Índice Randômico (IR) é fixo e tem como base o número de critérios avaliados (Tabela 9).

$$
\text { Equação 4. } R C=\frac{I C}{I R}
$$

Tabela 9. Valores de IR usados como referência para as matrizes de comparações par-a-par.

\begin{tabular}{|c|c|c|c|c|c|c|c|c|c|c|}
\hline VALOR REFERÊNCIA & 1 & 2 & 3 & 4 & 5 & 6 & 7 & 8 & 9 & 10 \\
\hline VALOR APLICADO & 0 & 0 & 0.58 & 0.9 & 1.12 & 1.24 & 1.32 & 1.41 & 1.45 & 1.49 \\
\hline
\end{tabular}

Fonte: Autores.

\section{Resultados e Discussão}

As Figuras 9 e 10 apresentam a evolução da expansão do uso e ocupação do solo no lixão de Coxim, entre 2003 a 2018. A área apresentou grande expansão, com deposição de resíduos a céu aberto. Diversos problemas socioambientais são provenientes desse tipo de atividade. Primeiro, é importante mencionar os catadores que lá exerciam sua principal fonte de renda, a catação de resíduos passíveis de reciclagem. Esse tipo de atividade fere os princípios da dignidade humana, onde indivíduos são expostos a condições insalubres de trabalho como a objetos perfurocortantes e infecções (CAVALCANTE et al., 2014).

Ainda, na catação dos metais, fogo era ateado nos resíduos para que o cobre, por exemplo, fosse facilmente encontrado pelos catadores, o que pode ser identificado na Figura 10 B, nas áreas enegrecidas. Isso ocasionava a degradação da qualidade do ar pela emissão de Gases de Efeito Estufa.

A deposição dos resíduos a céu aberto ainda ocasiona sérios problemas de saúde pública, onde vetores de doenças podem causar sérios danos à comunidade próxima. O lixão se encontrava a 1,5 quilômetro de distância do núcleo urbano de Coxim, e a 1,3 quilômetro do Rio Coxim, com alto potencial para contaminação do lençol freático ou por escoamento superficial. 
Figura 9. Área inadequada de disposição final de resíduos de Coxim, MS. Imagem de 17/06/2003.

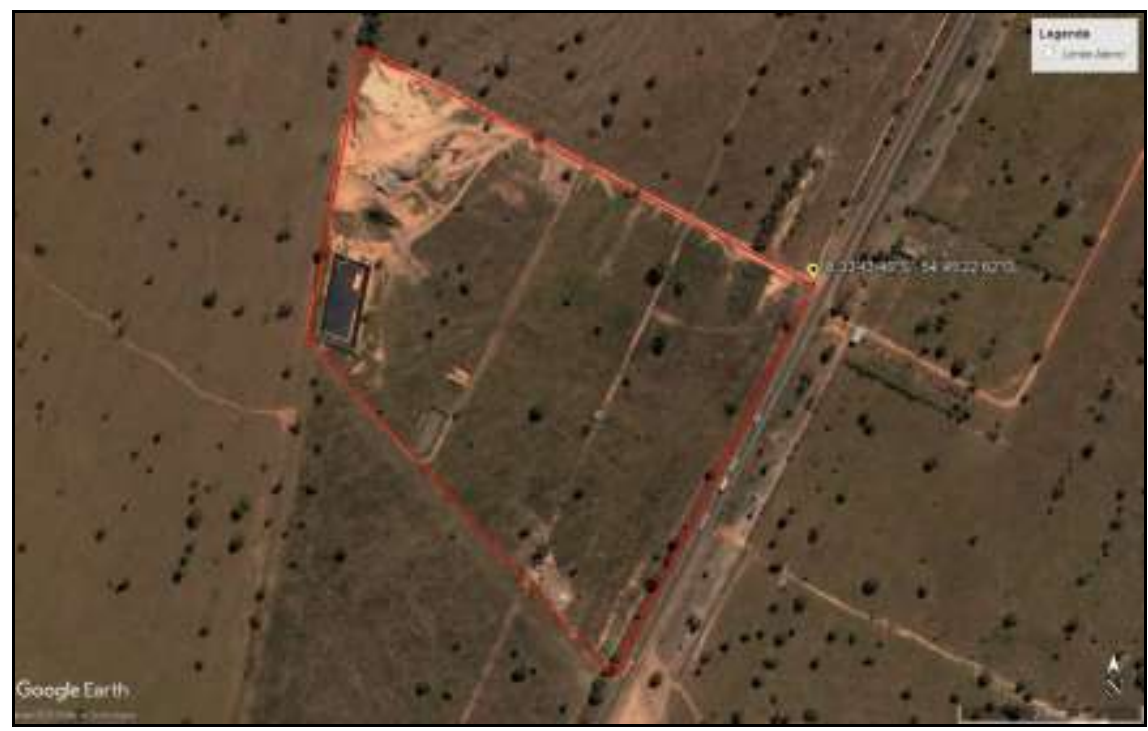

Fonte: Autores.

Figura 10. Área inadequada de disposição final de resíduos de Coxim, MS. Imagem de 01/08/2018.

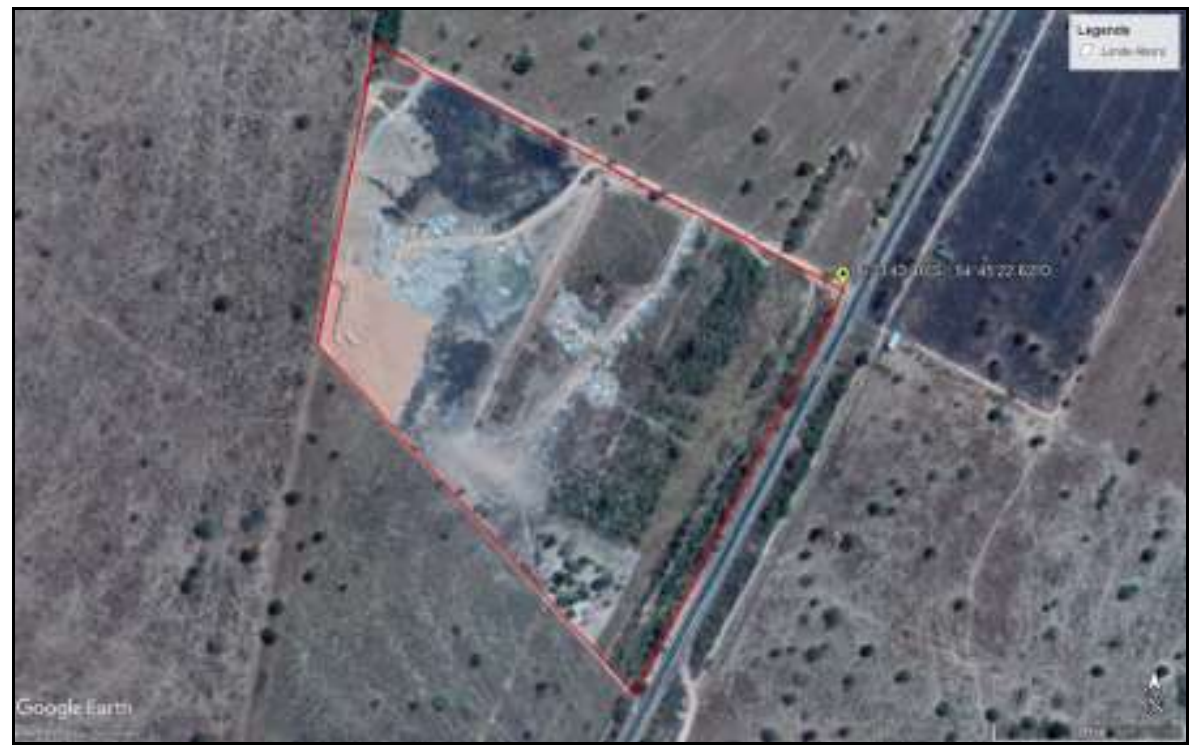

Fonte: Autores.

\subsection{Mapa de aptidão para implantação de aterro sanitário no município de Coxim}

Esse trabalho apresenta o mapa de aptidão para implantação de aterro sanitário no município de Coxim, como visualizado na Figura 11. O município apresenta muitas áreas com Alta aptidão para alocação de aterros sanitários, com um total de 32,13\% da área total do município; o segundo maior valor, 28,07\%, condiz à áreas com Baixa Aptidão; seguidos por áreas com Muito Baixa Aptidão, 27,12; e áreas com Muito Alta Aptidão, com 12,68\%, como apresentado na Tabela 10. 
Figura 11. Mapa de aptidão de áreas para implantação de aterro sanitário no município de Coxim, MS.

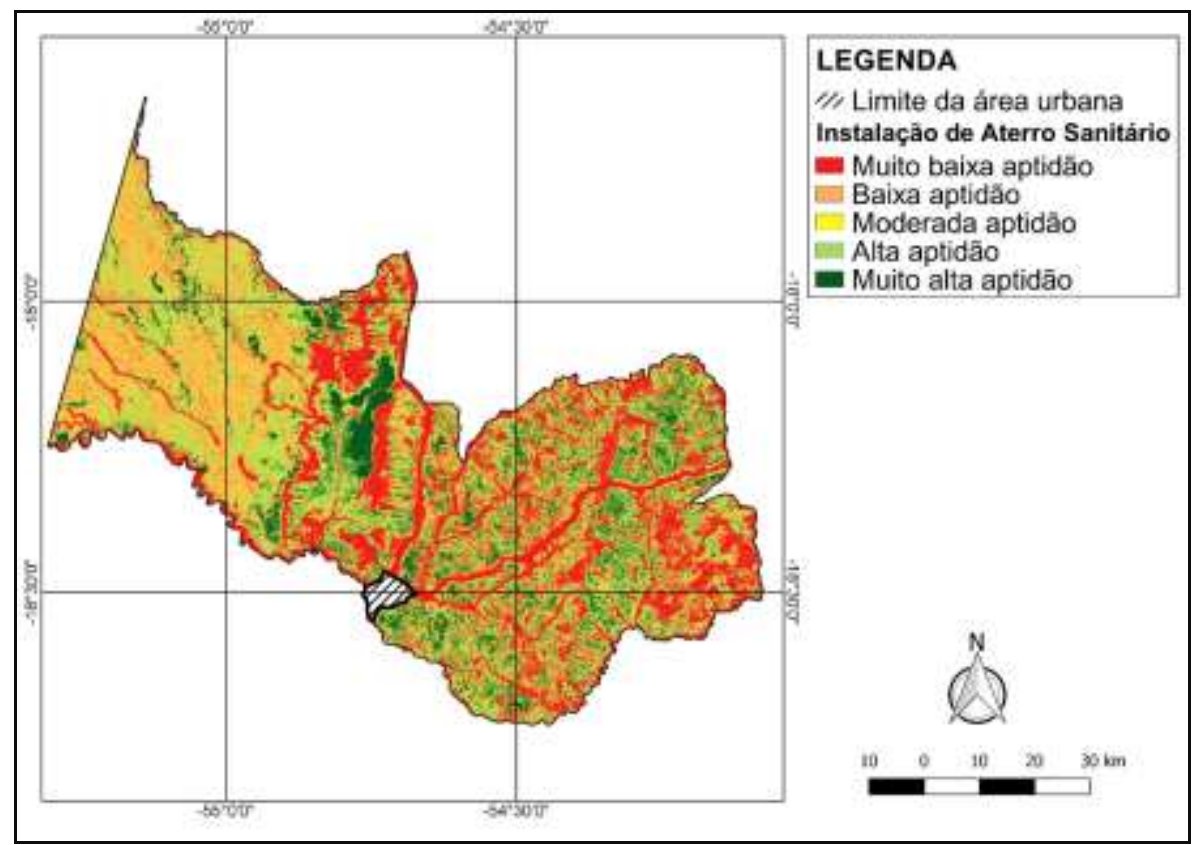

Fonte: Autores.

Tabela 10. Valores para áreas do mapa de aptidão para implantação de aterro sanitário no município de Coxim.

\begin{tabular}{cc}
\hline CLASSE & ÁREA $(\%)$ \\
\hline Muito baixa aptidão & 27,12 \\
Baixa aptidão & 28,07 \\
Alta aptidão & 32,13 \\
Muito alta aptidão & 12,68 \\
\hline
\end{tabular}

Fonte: Autores.

Em relação aos aspectos ambientais, o Município de Coxim encontra-se na entrada do Pantanal. Em seus limites estão confluências dos principais contribuintes do rio Taquari, que forma um importante, o maior, megaleque fluvial na planície pantaneira. Nesse âmbito, é imprescindível o correto manejo dos resíduos sólidos.

No que tange aos aspectos sociais, o município possui um dos menores índices de desenvolvimento humano do Estado. Isso implica em diversas famílias tirarem seu sustento de serviços de catação informais. Até o fim do ano de 2018 o lixão do município ainda estava ativo. O que implica em indivíduos executando atividades de catação em condições de trabalho insalubres e que ferem as necessidades mínimas de condições de trabalho.

\section{Conclusão}

O Município de Coxim possui posição estratégica para conservação de recursos hídricos nos biomas Cerrado e Pantanal. O modelo de expansão urbana, com aumento da densidade demográfica causou crescimento da quantitativo e qualitativo de resíduos. O município, até o fim do ano de 2018, enviava seus resíduos para o lixão, dispostos a céu aberto. Essa atividade causa sérios problemas relacionados a saúde pública devido a sua proximidade ao núcleo urbano. Com o fechamento do lixão, o município começou a enviar seus resíduos para Campo Grande, causando grande ônus econômico para a sociedade e com alta pegada ecológica.

Assim, esse trabalho identifica áreas aptas a implantação de aterros sanitários. Os critérios utilizados dispõem de valores restritivos relacionados a declividade, proximidade a malha urbana, malha rodoviária, a corpos hídricos, uso e 
ocupação do solo, áreas protegidas e vegetação nativa. Concluindo que $45 \%$ do território do município contém áreas de alta aptidão para implantação. A principal implicação dessa pesquisa é a possibilidade de dar respaldo à tomadores de decisão do município para elaboração de projetos junto às políticas públicas para melhoria da gestão de resíduos sólidos.

O Inciso VIII do Artigo $3^{\circ}$ da Política Nacional de Resíduos Sólidos (Lei 12.035/2010) estipula que a única maneira de disposição final ambientalmente adequada de resíduos sólidos domésticos é o aterro sanitário. Corrobora com essa exigência o Inciso V do Artigo 15 desta mesma lei, que coloca como uma das metas do Plano Nacional de Resíduos Sólidos a eliminação de lixões. A presente pesquisa demonstrou a dificuldade de se encontrar uma área apta à implantação de um aterro sanitário, pois há vários critérios que precisam ser obedecidos e que, inclusive, estão descritos na Norma Técnica NBR 13.896 da Associação Brasileira de Normas Técnicas. Diante dessa exigência legal implantação de aterros sanitários e a dificuldade apresentada para encontrar áreas aptas, sugere-se que novas pesquisas semelhantes a esta aqui apresentada sejam elaboradas noutros municípios brasileiros a fim de que, a legislação ambiental seja obedecida e se preservem os recursos naturais.

\section{Agradecimentos}

Ao CNPq pela concessão de Bolsa Produtividade em Pesquisa a Antonio Conceição Paranhos Filho (PQ-1D - CNPq Processo 305013/2018-1).

Agradecemos ainda a CAPES pelo acesso ao Portal de Periódicos.

Os autores agradecem ainda ao Programa de Pós-Graduação em Direito, da Faculdade de Direito (FADIR) da Fundação Universidade Federal de Mato Grosso do Sul (UFMS).

O presente trabalho foi realizado com apoio da Fundação Universidade Federal de Mato Grosso do Sul - UFMS/MEC - Brasil.

\section{Referências}

Abrelpe (2021). Panorama dos resíduos sólidos no brasil edição 2020 com novo formato, novas análises e informações inéditas. Associação Brasileira de Empresas de Limpeza Pública e Resíduos Especiais (ABRELPE). http: https://abrelpe.org.br/panorama/.

Ana. (2017). Atlas esgotos: despoluição de bacias hidrográficas. Agência Nacional de Águas (ANA). Brasília. https://metadados.snirh.gov.br/geonetwork/srv/api/records/1d8cea87-3d7b-49ff-86b8-966d96c9eb01.

Ana. (2019). Sistema Hidroweb. Agência Nacional de Águas (ANA). Brasília. http://www.snirh.gov.br/hidroweb.

Bonham-Carter, G. F. (1995). Geographic Information Systems for Geoscientists: Modelling with GIS. Ontario: Delta Printing Ltd., 398 p.

Cavalcante, L. P. S., Alencar, L. D. \& Barbosa, E. M. (2014). Conflitos socioambientais e catadores de materiais recicláveis informais: estudo de caso dm Campina Grande/PB. Revista Polêm!ca, 13(1), 1034-56.

CETESB. (1997). Aterro Sanitário. Apostilas Ambientais. - Companhia de Tecnologia de Saneamento Ambiental (CETESB). São Paulo, 40 p.

Colman, C. B.; Lima, D. L; Silva, N. M. \& Paranhos Filho, A. C. (2016). Análise Regional para Implantação de Aterro Sanitário Utilizando Software Livre. Anuário do Instituto de Geociências. 39(3), 98-104.

Dalmas, F. B.; Goveia, S. S.; Oliveira, F. R..; Amaral, C. H. \& Macedo, A. B. (2011). Geoprocessamento aplicado à gestão de resíduos sólidos na UGRHI-11 - Ribeira de Iguape e Litoral Sul. São Paulo, UNESP, Geociências, 30(2), 285-299.

Franceschi, F. R. A., Santiago, C. D., De Lima, T. Q., \& Pugliesi, E. (2017) Panorama dos resíduos sólidos no Brasil: uma discussão sobre a evolução dos dados no período 2003-2014. Revista DAE, 65, 62-68.

Deus, R. M.; Battistelle, R. A. G. \& Silva, G. H. R. (2015). Resíduos sólidos no Brasil: contexto, lacunas e tendência. Engenharia Sanitária e Ambiental, 19, 685-698.

DNIT. (2021). VGeo: Visualizador de Informações Geográficas do Departamento Nacional de Infraestrutura de Transportes. - Departamento Nacional de Infraestrutura de Transportes (DNIT). http://servicos.dnit.gov.br/vgeo/.

GOOGLE (2021). Google Earth website. http://earth.google.com/.

IBGE. (2021). População do Município de Coxim/MS, no ultimo Censo. 2019. - Instituto Brasileiro de Geografia e Estatística. https://cidades.ibge.gov.br/brasil/ms/coxim/panorama. 
Research, Society and Development, v. 10, n. 13, e135101320992, 2021

(CC BY 4.0) | ISSN 2525-3409 | DOI: http://dx.doi.org/10.33448/rsd-v10i13.20992

INPE (2011). TOPODATA: Banco de dados Geomorfométricos do Brasil. - Instituto Nacional de Pesquisas Espaciais (INPE). http://www.dsr.inpe.br/topodata/.

IPT (2000). Compromisso Empresarial para Reciclagem. Lixo Municipal: Manual de Gerenciamento Integrado. - Instituto de Pesquisas Tecnológicas (IPT). Coordenação: Maria Luiza Otero D’Almeida, André Vilhena. São Paulo: IPT/CEMPRE. 2 a. ed.

Lima, L. M. Q. (1995). Lixo: Tratamento e Biorremediação. Editora Hemus, 3 ed., 265 p.

NURENE. (2008). Resíduos Sólidos: projeto, operação e monitoramento de aterros sanitários: guia do profissional em treinamento: nível 2. - Núcleo Regional Nordeste (NURENE). Secretaria Nacional de Saneamento Ambiental (org). - Salvador: ReCESA, 113 p.

Poague, K. I. H. M.; Silva, W. R.; Rezende, V. M.; Pereira, A. P. M.; Árabe, M. P. (2018). SIG na seleção de áreas para implantação de aterros sanitários: estudo de caso em Jundiaí-SP. Revista DAE, 66(213), 59-75.

Saaty, T. L. (1990). How to make a decision: the analytic hierarchy process. European Journal of Operational Research. North Holland, 48, 9-26. 